Fidei: Jurnal Teologi Sistematika dan Praktika, Vol. 4, No. 2, Des. 2021

Fidei: Jurnal Teologi Sistematika dan Praktika

Terakreditasi No: 85/M/KPT/2020 (Sinta 4)

e-ISSN: 2621-8135

http://www.stt-tawangmangu.ac.id/e-journal/index.php/fidei

Vol. 4 No.2 (Des. 2021) hlm: 226-244

p-ISSN: 2621-8151

Diterbitkan Oleh: Sekolah Tinggi Teologi Tawangmangu

\title{
Strategi PAIKEM Terpadu Pada Pembelajaran Pendidikan Agama Kristen di Era Pandemi Covid-19
}

\author{
Yuel Sumarno, Apin Militia Christi, Febie Yolla Gracia, \\ Anastasia Runesi, Hendrik Timadius ${ }^{1)^{*}}$ \\ 1) Sekolah Tinggi Teologi Bethel Indonesia, Indonesia \\ *) E-mail: yuels@gmail.com
}

Diterima: 28 Agt. 2021 Direvisi: 11 Nov. 2021

Disetujui: 30 Nov. 2021

\begin{abstract}
Abstrak
Menerapkan strategi pembelajaran merupakan peran penting dalam mewujudkan tujuan Pendidikan Agama Kristen di masa pandemi Covid-19. Tujuannya ialah meningkatkan perserta didik untuk melakukan kegiatan pembelajaran yang beragam secara kreatif, efektif dan efesien. Maka strategi yang cocok digunakan selama pandemi Covid-19 adalah strategi PAIKEM terpadu. Penulis akan melakukan analisis dan mendefinisikan strategi PAIKEM terpadu yang dilakukan oleh guru-guru pendidikan agama Kristen di masa pandemi Covid-19. Tujuan penelitian ini untuk mengetahui strategi PAIKEM terpadu bagi guru kepada siswa pendidikan agama Kristen di era pandemi Covid-19. Metode yang digunakan adalah Penelitian Tindakan Kelas (PTK). Hasil penelitian menunjukkan bahwa strategi PAIKEM efektif digunakan dalam PTK agar seluruh siswa lulus Kriteria Ketuntasan Minimal (KKM) dengan tiga siklus. Karena itu, dalam tataran kebijakan, strategi PAIKEM Terpadu dapat menjadi model pembelajaran wajib dalam meningkatkan ketercapaian KKM siswa.
\end{abstract}

Kata-Kata Kunci: Strategi PAIKEM; Karakter PAIKEM Terpadu; Pendidikan Agama Kristen; Pandemi Covid-19 


\section{Abstract}

Implementing learning strategies is an essential role in realizing the goals of Christian Religious Education during the Covid-19 pandemic. The goal is to increase students to carry out diverse learning activities creatively, effectively, and efficiently. So the strategy that is suitable for use during the Covid-19 pandemic is the integrated PAIKEM strategy. The author will analyze and define an integrated PAIKEM strategy carried out by Christian religious education teachers during the Covid-19 pandemic. The purpose of this study was to determine the integrated PAIKEM strategy for teachers to students of Christian religious education in the era of the Covid-19 pandemic. The method used is Classroom Action Research (CAR). The results showed that the PAIKEM strategy was effectively used in CAR so that all students passed the Minimum Completeness Criteria (MCC) with three cycles. Therefore, the Integrated PAIKEM strategy can be a mandatory learning model at the policy level in increasing students' MCC achievement.

Keywords: Christian Religious Education; Integrated PAIKEM character;

PAIKEM strategy; Pandemic Covid-19.

\section{Pendahuluan}

Pandemi covid-19 yang masih berlangsung, memaksa sistem pendidikan berubah dari pembelajaran luring menjadi pembelajaran online. Tentunya berbagai upaya telah dilakukan oleh pemangku kebijakan, stakeholder dan para pendidik agar pembelajaran online dapat berjalan dengan baik. ${ }^{1}$ Namun, kenyataannya di berbagai sekolah baik di perkotaan maupun di pedesaan mengalami masalah dalam proses pembelajaran. Permasalahan muncul akibat adaptasi dari pembelajaran langsung kepada pembelajaran online. Meskipun telah banyak dilakukan penelitian dan pelatihan untuk adaptasi dengan model belajar yang berubah, tetapi tingkat keberhasilan ketercapaian pendidikan masih menjadi masalah yang belum mendapat jalan terang. ${ }^{2}$

Berbagai penelitian terdahulu yang dipakai dalam penelitian ini sebagai acuan menunjukkan beberapa kendala dalam proses pembelajaran online. Siahaan mencatat masalah tugas dan materi yang dihadapi oleh guru dan siswa. ${ }^{3}$

${ }^{1}$ Agusmanto Hutauruk and Ropinus Sidabutar, "Kendala Pembelajaran Daring Selama Masa Pandemi Di Kalangan Mahasiswa Pendidikan Matematika: Kajian Kualiatatif Deskriptif," SEPREN: Journal of Mathematics Education and Applied 02, no. 01 (2020): 45-51.

${ }^{2}$ Lina Handayani, "Keuntungan, Kendala Dan Solusi Pembelajaran Online Selama Pandemi Covid-19 : Studi Ekploratif Di SMPN 3 Bae Kudus," Journal Industrial Engineering \& Management Research 1, no. 2 (2020): 16.

${ }^{3}$ Matdio Siahaan, "Dampak Pandemi Covid-19 Terhadap Dunia Pendidikan," Jurnal Kajian Ilmiah (JKI) 1, no. 1 (2020): 1-6. 
Seperti, guru yang mengganti materi pelajaran dan tugas yang lain padahal belum selesai materi sebelumnya diajarkan. Demikian dengan signal yang tidak stabil yang menyebabkan siswa tertinggal materi pelajaran sementara guru terus menerangkan materi yang telah disiapkan. ${ }^{4}$ Bahkan Basar menyoroti pembelajaran online dari hasil proses pembelajaran yang berupa ketercapaian KKM yang rendah. ${ }^{5}$ Faktor-faktor lain penghambat pembelajaran online mulai dari keterbatasan perangkat pembelajaran, akses internet yang kurang memadai, dan biaya pembelian kuota yang cukup memberatkan bagi orang tua (fakta). Selain itu juga ada beberapa kendala yang lain, seperti guru yang masih "gagap teknologi", pembelajaran yang membosankan dan tidak menarik perhatian siswa. ${ }^{6}$

Pembelajaran daring yang dilakukan di masa pandemi cenderung menyebabkan kebosanan dalam diri siswa. Beberapa guru, menjadi kurang kreatif melaksanakan pembelajaran di kelas. Observasi awal di lapangan didapati sikap cuek dari guru, seperti pembelajaran daring dilakukan dengan metode ceramah, bersifat satu arah, guru hanya memberikan tugas tanpa memberikan penjelasan. ${ }^{7}$ Bahkan beberapa siswa perlu mencari sendiri penjelasan di Youtube untuk mengerjakan tugas. Hal ini membuat beberapa siswa memilih untuk off camera; melakukan kegiatan yang lain di jam pelajaran serta beberapa juga tertidur pada saat pembelajaran di kelas. Akibatnya hasil belajar siswa di kelas menurun. ${ }^{8}$ Situasi pembelajaran daring yang demikian, perlu diubah dan dicarikan sebuah solusi. Hasil penelitian evaluasi mengenai program pembelajaran daring pada mata pelajaran pendidikan Agama Kristen menunjukkan bahwa implementasi pembelajaran daring masih lemah jika dilihat pada proses desain dari program pembelajaran daring tersebut, sehingga diperlukan model pembelajaran yang lebih kreatif, aktif, inovatif, efektif dan menyenangkan. Berdasarkan hal tersebut di atas, peneliti kemudian mencoba

${ }^{5}$ Afip Miftahul Basar, "Problematika Pembelajaran Jarak Jauh Pada Masa Pandemi Covid-19," Edunesia : Jurnal Ilmiah Pendidikan 2, no. 1 (2021): 208-218.

${ }^{6}$ Markus Oci, "Pengaruh Pengelolaan Kelas Dalam Pelajaran Agama Kristen Terhadap Prestasi Belajar Siswa Di SMP Kanaan Ungaran Tahun Ajaran 2017-2018," FIDEI: Jurnal Teologi Sistematika dan Praktika 1, no. 2 (2018): 199-218.

${ }^{7}$ Jakson Sespa Toisuta, "Peran Dosen Mengatasi Permasalahan Pembelajaran Online Pada Masa Pandemi Covid-19," Fidei: Jurnal Teologi Sistematika dan Praktika 4, no. 1 (2021): 23-42.

${ }^{8}$ Priskila Issak Benyamin, Ibnu Salman, and Frans Pantan, "Evaluasi Pembelajaran Daring Pendidikan Agama Kristen Di Masa Pandemi," Jurnal Teologi Berita Hidup 4, no. 1 (2021): 52-59. 
menerapkan pembelajaran PAIKEM terpadu di kelas daring. Karena melalui pembelajaran PAIKEM terpadu yang merupakan pembelajaran aktif, inovatif, kreatif, efektif dan menyenangkan dapat memecahkan suasana monoton di kelas. Sehingga siswa dapat menjadikan kelas lebih aktif dan tertantang untuk mengikuti pembelajaran daring. Selain itu pembelajaran PAIKEM juga dapat meningkatkan prestasi belajar siswa. Karena mendorong siswa untuk memiliki kemandirian belajar sehingga dapat menciptakan merdeka belajar.

Hal ini menjadi perhatian bagi guru yang mengajar dikelas. Memang berbagai upaya telah dilakukan oleh guru, namun hasil dari pembelajaran di kelas masih kurang maksimal. ${ }^{9}$ Sehingga perlu dicari sebuah strategi pembelajaran yang tepat sebagai salah satu solusi untuk mencapai hasil maksimum kelulusan KKM. Berdasarkan pemaparan di atas, maka pada penelitian ini penulis menerapkan strategi pembelajaran PAIKEM terpadu untuk meningkatkan hasil pembelajaran ${ }^{10}$ Pendidikan Agama Kristen (PAK) secara khusus di SMP Negeri 2 Legok, Banten untuk meningkatkah hasil ketercapaian KKM mata pelajaran PAK.

Pembelajaran PAIKEM Terpadu sudah pernah diteliti oleh Yulita Matulessy, Vivi Guslauw dan Shintya Lumasina menunjukkan bahwa pembelajaran PAIKEM cocok diterapkan di masa pandemi untuk mewujudkan merdeka belajar siswa. ${ }^{11}$ Hal senada juga dikemukakan oleh Ina Magdalena, Nevi Septianti, Liza Barlianty dan Sitti Aisyah Farawansya bahwa penerapan model pembelajaran PAIKEM Gembrot dapat meningkatkan hasil belajar siswa di masa pandemi Covid-19. ${ }^{12}$ Anindia Impriyana dalam penelitiannya yang juga menemukan bahwa penggunaan media power point pada sistem pembelajaran PAIKEM sangat membantu siswa untuk aktif dalam proses pembelajaran dan mendorong guru untuk kreatif di masa pandemi. ${ }^{13}$ Berdasarkan pada penelitian-

${ }^{9}$ Sarah Busyra and Lutfiah Sani, "Kinerja Mengajar Dengan Sistem Work From Home (WFH) Pada Guru Di SMK Purnawarman Purwakarta," IQ (Ilmu Al-qur'an): Jurnal Pendidikan Islam 3, no. 01 (2020): 1-16.

${ }^{10}$ Abdul Malik, "Penerapan Model PAIKEM Dalam Meningkatkan Hasil Belajar," Education and Learning Journal 1, no. 1 (2020): 50.

11 Yulita Matulessy, Vivi Guslauw, And Shintya Lumasina, "Metode Pembelajaran Paikem Dalam Mewujudkan Merdeka Belajar Siswa Di Masa Pandemi Covid-19 Paikem' S Learning Methods In Realizing Students ' Learning Independence During The Covid-19 Pandemic" (2021).

12 Ina Magdalena et al., "Penerapan Model Pembelajan Paikem Gembrot Dimasa Pandemi Covid-19 Terhadap Peningkatan," EDISI: Jurnal Edukasi dan Sains 2 (n.d.): 348-365.

13 Anindia Impriyan, "Penggunaan Media Power Point Dalam Pelaksanaan Sistem PAIKEM Pada Mata Pelajaran Fikih Kelas IX Pada Masa Pandemi Covid-19 Di MTs Nahdlotussibyan Wonoketingal Karangayar Demak" (IAIN Kudus, 2020). 
penelitian terdahulu yang diuraikan di atas, maka novelty penelitian ini adalah mengenai penggunaan strategi PAIKEM pada pembelajaran Pendidikan Agama Kristen, yang cukup berbeda dengan penelitian yang sebelumnya. Selain itu lokus penelitian dan metode penelitian yang digunakan juga berbeda dengan penelitian yang terdahulu. Peneliti menggunakan metode penelitian tindakan kelas pada Siswa Menengah Pertama sedangkan ketiga penelitian terdahulu dilakukan kepada tingkat Sekolah Dasar.

\section{Metode Penelitian}

Pada penelitian ini menggunakan metode penelitian tindakan atau yang dikenal dengan action research. Karakteristik dari metode ini dengan memberikan solusi langsung pada permasalaha yang ditemukan di kelas. ${ }^{14}$ Tahapan-tahapan yang ada dalam penelitian tindakan kelas berupa pelaksanaan siklus. Dimana dalam siklus itu terdapat beberapa poin-poin penting seperti pada bagan di bawah ini:

\section{Gambar 1. Model PTK}

\section{MODEL PENELITIAN TINDAKAN KELAS}

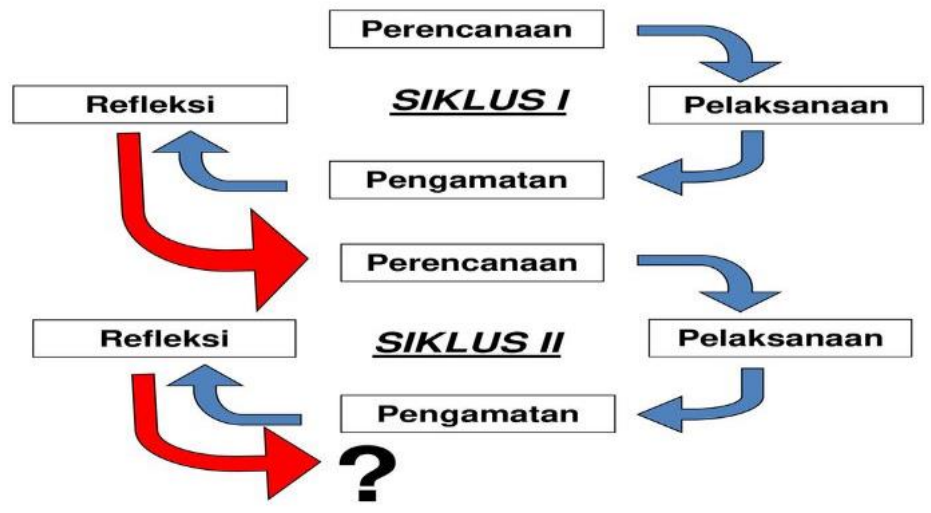

Tahapan-tahapan dalam model peneltian tindakan kelas yaitu perencanaan, pelaksanaan, pengamatan dan refleksi. Adapun jumlah siklus yang dilakukan pada metode ini tidak dibatasi dengan catatan akan jenuh, jika sudah berhasil mencapai kriteria yang ditetapkan. ${ }^{15}$

Penelitian dilakukan di SMP Negeri 2 Legok Banten pada mata pelajaran PAK. Alasan implementasi dilakukan pada tempat ini karena (i) Peneliti adalah

${ }^{14}$ Ade Haerullah and Said Hassan, PTK \& Inovasi Guru, ed. Eko Purnomo and Hernita Pasongli, cetakan 1. (Ponorogo: Uwais Inspirasi Indonesia, 2021).

${ }^{15}$ Trianto, Model Pembelajaran Terpadu: Konsep, Strategi, Dan Implementasinya Dalam Kurikulum Tingkat Satuan Pendidikan (Jakarta: Bumi Aksara, 2011). 
salah satu volunteer pengajar PAK di SMP Negeri 2 Legok; (ii) Masa SMP dapat dikategorikan masa puber yaitu masa pertumbuhan dan perubahan yang cepat seperti yang dikatakan Djwandono bahwa masa puber dan remaja mampu untuk memerbaiki, menganalisis, membandingkan dan memutarbalikan hubungan yang abstrak merupakan pengalaman yang akan mendasari keterampilan yang diperlukan setelah mereka menjadi orang dewasa ${ }^{16}$; (iv) SMP Negeri Legok 2 Banten ini, memiliki siswa yang terdiri dari berbagai suku. Siswa yang beragama Kristen, bergereja pada denominasi gereja (Kristen Katholik, Kristen Protestan serta Kristen Karismatik). Pekerjaan orangtua mereka antara lain ada yang bertani, pedagang, supir angkot, wiraswasta dan beternak binatang babi. Tempat tinggal mereka ada yang di kota dan juga ada yang di desa. Melihat kenyataan di atas, maka dalam proses pembelajaran akan memunculkan berbagai permasalahan belajar dan prilaku yang bervariasi. ${ }^{17}$

\section{Pembahasan dan Hasil}

Pada penelitian imlementasi ini dilakukan tiga siklus untuk melihat ketercapaian kriteria yang telah ditetapkan. Dalam proses pembelajaran tentunya kriteria ketuntasan minimal atau KKM menjadi salah dari kriteria tersebut. Dalam penelitian ini juga menggunakan nilai pembelajaran untuk melihat ketuntasan KKM mata pelajaran PAK.

Siklus 1 pembelajaran PAK disebut juga sebagai kondisi awal penelitian sebelum menerapkan Strategi PAIKEM terpadu. Pada siklus pembelajaran dilakukan sesuai Rencana Pembelajaran Pelaksanaan (RPP). Kemudian diakhir pembelajaran dilakukan tes untuk melihat ketuntasan pembelajaran berdasarkan KKM. Adapun KKM pembelajaran PAK yang ditetapkan yaitu 78. Jumlah peserta didik adalah 29 peserta didik yang mana terdiri dari 12 wanita dan 17 laki-laki, pada tahun ajaran 2020/2021 yang ikut pembelajaran mata pelajaran PAK.

\section{Deskripsi Data Siklus 1 SMP Negeri 2 Legok Banten}

Tahap Perencanaan

Tahap perencanaan tindakan yang dilakukan pada siklus I meliputi penyusunan rencana pelaksanaan pembelajaran tanpa dilengkapi dengan strategi

\footnotetext{
${ }^{16}$ Sri Esti Wuryani Djwandono, Psikologi Pendidikan (Jakarta: Gramedia Widiasarana Indonesia, 2006).

${ }^{17}$ Dewi Indrapangastuti, "Praktek Dan Problematik Pendidikan Multikultural Di SMK," Jurnal Pembangunan Pendidikan: Fondasi dan Aplikasi 2, no. 1 (2014): 13-25.
} 
PAIKEM Terpadu. Penyusunan rencana pelaksanaan pembelajaran (RPP) dilakukan dengan cara memerbaiki dengan menyesuaikan program pembelajaran yang telah dibuat di awal semester. Lembar pengamatan guru dirancang untuk melakukan pengamatan pada aspek guru, guru mengucapkan salam, berdoa, mengisi daftar hadir, menyampaikan indikator, tujuan pembelajaran, memberikan apersepsi, mengajar dengan menggunakan media pembelajaran secara kontekstual, melakukan inovasi baru dengan menggunakan media dalam belajar, dapat menguasai kondisi kelas, memberikan kesempatan anak untuk bertanya, menguasai materi yang diajarkan serta memberikan materi dengan bantuan media yang sesuai, memberikan postes, menyimpulkan pelajaran dan doa penutup. ${ }^{18}$

\section{Tahap Pelaksanaan RPP}

Pada tahap pelaksanaan, kegiatan dimulai dengan pendahuluan yang terdiri dari beberapa kegiatan yaitu; (i) Guru masuk memberi salam dan doa bersama peserta didik; (ii) Guru melakukan presensi; (iii) Guru melakukan apersepsi? (bertanya); (iv) Guru menginformasikan topik dan tujuan pembelajaran sesuai meteri yang akan dipelajari; (v) Guru memberikan motivasi kepada peserta didik agar bersemangat belajar; (vi) Guru menyiapkan media pembelajaran yang akan digunakan. Selanjunya melakukan kegiatan inti yang terbagi menjadi tiga bagian, yaitu Eksplorasi yang terdiri dari guru menyiapkan materi yang akan dipelajari yaitu "Allah Maha Pengampun" dan guru menyampaikan materi hanya dengan menggunan media share screen powerpoint. Kedua, Elaborasi yaitu guru memberikan beberapa pertanyaan mengenai materi yang sudah disampaikan. Terakhir konfirmasi dengan kegiatan guru memberikan penguatan kepada peserta didik yang berhasil menjawab pertanyaan dengan benar dan memberikan motivasi kepada peserta didik yang belum optimal dalam mengikuti kegiatan pembelajaran. Bagian terakhir adalah penutup yang terdiri dari kegiatan, (i) Guru bersama peserta didik menyimpulkan materi yang sudah dibahas (refleksi); (ii) Peserta didik diberi kesempatan untuk bertanya; (iii) Guru memberikan soal evaluasi; (iv) Hasil pengerjaan diberikan kepada guru; (v) Guru menutup pembelajaran (doa dan salam).

18 Agus Suprijono, Cooperatif Learning, Teori Dan Aplikasi PAIKEM, 5th ed. (Yogyakarta: Pustaka Pelajar, 2011). 


\section{Hasil Pengamatan}

Hasil pengamatan PAK di SMP Negeri 2 Legok diperoleh dengan melakukan tes tertulis pada akhir pelajaran. Dari 29 peserta didik, yang tuntas atau memenuhi KKM 4 orang (13\%) sedangkan yang tidak memenuhi KKM 25 orang (86\%). Hal ini menunjukan bahwa prestasi belajar PAK di SMP Negeri 2 Legok sangat rendah. Rendahnya prestasi belajar peserta didik pada siklus I dapat dilihat pada tabel berikut:

Tabel 1. Hasil Tes Tertulis SMP Negeri 2 Legok Siklus I

\begin{tabular}{ccc}
\hline No & Aspek & Nilai \\
\hline 1 & Nilai Terendah & 70 \\
\hline 2 & Nilai Tertinggi & 80 \\
\hline 3 & Rata-rata Nilai & 73,3 \\
\hline
\end{tabular}

Hasil pengamatan menunjukan terdapat 4 peserta didik (13\%) memeroleh prestasi belajar PAK berupa hasil tes tertulis lebih besar atau sama dengan 78 (memenuhi KKM) pada siklus II. Hal ini menunjukan prestasi belajar PAK sangat rendah. Ketuntasan hasil belajar PAK berdasarkan hasil tes tertulis sebesar 13\% atau 4 orang dari 29 peserta didik. Hal ini menunjukan bahwa hasil belajar PAK berupa nilai tes tertulis peserta didik SMP Negeri 2 Legok sangat rendah. Hasil pengamatan peran guru dalam menerapkan pembelajaran simulasi pada pembelajaran PAK diamati dengan menggunakan lembar observasi. Ada sebelas yang diamati yaitu lembar pengamatan guru dirancang untuk melakukan pengamatan pada aspek guru, guru mengucapkan salam, berdoa, mengisi daftar hadir, menyampaikan indikator, tujuan pembelajaran, memberikan apersepsi, mengajar dengan menggunakan media pembelajaran secara kontekstual, melakukan inovasi baru dengan menggunakan media dalam belajar, dapat menguasai kondisi kelas, memberikan kesempatan anak untuk bertanya, menguasai materi yang diajarkan serta memberikan materi dengan bantuan media yang sesuai, memberikan postes, menyimpulkan pelajaran dan doa penutup.

\section{Refleksi Siklus I}

Refleksi pengamatan guru pada siklus I di SMP Negeri 2 Legok mencapai 3,5. Dalam pelaksanaan tindakan ada beberapa hal yang menjadi catatan penting yaitu: (i) Guru perlu memerhatikan setiap kegiatan peserta didik secara 
menyeluruh agar peserta didik mampu memerhatikan pembelajaran dengan baik; (ii) Guru perlu mengingatkan peserta didik untuk mencatat materi pelajaran yang disampaikan; (iii) Guru perlu membimbing peserta didik yang kurang aktif dalam pembelajaran.

\section{Deskripsi Data Siklus 2 SMP Negeri 2 Legok Banten}

\section{Tahap Perencanaan}

Tahap perencanaan tindakan yang dilakukan pada siklus II meliputi penyusunan rencana pelaksanaan pembelajaran yang dilengkapi dengan strategi PAIKEM Terpadu lembar pengamatan. Penyusunan rencana pelaksanaan pembelajaran (RPP) dilakukan dengan cara memerbaiki dengan menyesuaikan program pembelajaran yang telah dibuat di awal semester. RPP disusun sesuai dengan model RPP yang dilengkapi strategi PAIKEM Terpadu. Pada RPP kondisi awal yang adalah siklus pertama belum menerapkan strategi PAIKEM Terpadu. Jadi pembelajaran pada siklus pertama masih menggunakan metode ceramah biasa tanpa menerapkan strategi PAIKEM.

Lembar pengamatan guru dirancang untuk melakukan pengamatan pada aspek guru, guru mengucapkan salam, berdoa, mengisi daftar hadir, menyampaikan indikator, tujuan pembelajaran, memberikan apersepsi, mengajar dengan menggunakan media pembelajaran secara kontekstual, melakukan inovasi baru dengan menggunakan media dalam belajar, dapat menguasai kondisi kelas, memberikan kesempatan anak untuk bertanya, menguasai materi yang diajarkan serta memberikan materi dengan bantuan media yang sesuai, memberikan postes, menyimpulkan pelajaran dan doa penutup.

\section{Tahap Pelaksanaan Tindakan}

Pada tehap pelaksanaan, kegiatan belajar dimulai dengan pendahuluan yang berisi (i) Guru masuk memberi salam dan doa bersama peserta didik; (ii) Guru melakukan presensi; (iii) Guru melakukan apersepsi? (Bertanya); (iv) Guru menginformasikan topik dan tujuan pembelajaran sesuai meteri yang akan dipelajari; (v) Guru memberikan motivasi kepada peserta didik agar bersemangat belajar; (vi) Guru menyiapkan media pembelajaran yang akan digunakan.

Kegiatan selanjutnya adalah kegiatan inti PAK dari strategi PAIKEM Terpadu yang terdiri dari 3 bagian, yaitu ekplorasi yang dilakukan dengan (i) Guru menyiapkan materi yang akan dipelajari yaitu "Mengampuni sesama manusia"; (ii) Guru menunjukkan media terkait materi: Balon dan Sulap Tali 
Temali; (iii) Guru memberikan pertanyaan pada peserta didik terkait dengan media (bertanya); (iv) Guru memberikan umpan balik terhadap jawaban peserta didik. Bagian kedua adalah elaborasi yang terdiri dari (i) guru membagi peserta didik dalam beberapa kelompok (disesuaikan dengan jumlah peserta didik dikelas); (ii) guru membagi media, dan lembar kerja sebagai bahan diskusi pada tiap kelompok; (iii) setiap kelompok ditugaskan untuk melakukan pengamatan (Inkuiri); (iii) peserta didik bersama kelompoknya mendiskusi hasil pengamatan kemudian menuliskan dilembar kerja (Masyarakat belajar); (iv) Setiap kelompok mempresentasikan hasil diskusi (pemodelan); (v) kelompok lain memberi tanggapan. Bagian terakhir adalah Konfirmasi yang terdiri dari kegiatan (i) guru memberikan konfirmasi terhadap hasil kerja peserta didik (refleksi); (ii) guru memberikan penguatan (reinforcement) kepada peserta didik yang berhasil menjawab pertanyaan dengan benar; (iii) guru memberikan motivasi kepada peserta didik yang kurang optimal dalam mengikuti kegiatan pembelajaran. ${ }^{19}$

\section{Hasil Pengamatan}

Pada siklus II proses pembelajaran PAK dilakukan dengan menerapkan Strategi PAIKEM Terpadu pada materi mengampuni sesama manusia disertai pengamatan hasil belajar peserta didik disertai pengamatan guru di sekolah SMP Negeri 2 Legok. Hasil pengamatan belajar PAK diperoleh dengan melakukan tes tertulis pada akhir pelajaran. Dari hasil pengamatan dengan menggunakan strategi PAIKEM Terpadu. Dalam strategi PAIKEM Terpadu, peserta didik dibagi dalam beberapa kelompok, dalam kelompok peserta didik sangat antusias mengikuti pembelajaran. Dalam proses pembelajaran tersebut, guru menggunakan media tali magic, film, power poin.

Hasil belajar PAK di SMP Negeri 2 Legok berupa hasil tes tertulis ulangan harian semester ganjil rata-rata telah memenuhi standar kriteria ketuntasan minimal (KKM) yaitu 78. Dari 29 peserta didik, yang tuntas atau memenuhi KKM 15 orang (51,7\%). Hal ini menunjukan bahwa prestasi belajar PAK di SMP Negeri 2 Legok meningkat dari siklus 1. Tingginya prestasi belajar peserta didik pada siklus I dapat dilihat pada tabel 1 berikut:

${ }^{19}$ Lisa Gitleman, "Penerapan Metode PAIKEM Untuk Hasil Belajar Siswa Dalam Mata Pelajaran Pendidikan Agama Kristen Di Kelas VB SD Inpres Oebufu Kupang," Paper Knowledge . Toward a Media History of Documents 1, no. 2 (2014): 15-20. 
Tabel 2. Hasil Tes Tertulis SMP Negeri 2 Legok Siklus II

\begin{tabular}{ccc}
\hline No & Aspek & Nilai \\
\hline 1 & Nilai Terendah & 70 \\
\hline 2 & Nilai Tertinggi & 85 \\
\hline 3 & Rata-rata Nilai & 77,5
\end{tabular}

Hasil pengamatan menunjukan terdapat 15 peserta didik $(51,7 \%)$ memeroleh hasil belajar PAK berupa hasil tes tertulis lebih besar atau sama dengan 78 (memenuhi KKM) pada siklus II. Sedangkan yang tidak tuntas sebanyak 14 orang $(48,3 \%)$. Hal ini menunjukan hasil belajar PAK sangat baik. Data tersebut dapat divisualisasi dengan grafik berikut:

\section{Refleksi Siklus 2}

Peran guru dalam menerapkan strategi PAIKEM Terpadu pada materi pokok "pengampunan bagi sesama manusia" masih belum berdampak secara menyeluruh kepada ketercapaian KKM. Meskipun demikian, terdapat kenaikan $38,7 \%$ dari siklus I yang secara presentase cukup baik. Refleksi pengamatan guru pada siklus II memiliki skor rata-rata 4,9. Dalam pelaksanaan tindakan ada beberapa hal yang menjadi catatan penting yaitu: (i) Guru perlu memerhatikan setiap kegiatan peserta didik secara menyeluruh agar peserta didik mampu memerhatikan pembelajaran dengan baik; (ii) Guru perlu mengingatkan peserta didik untuk mencatat materi pelajaran yag disampaikan; (iii) Strategi PAIKEM Terpadu menuntut guru untuk kreatif dalam mengajar, sehingga membuat tidak membosankan; (iv) Guru perlu membimbing peserta didik yang kurang aktif dalam kelompok.

\section{Deskripsi Data Hasil Siklus III}

\section{Tahap Perencanaan}

Tahap perencanaan tindakan yang dilakukan pada siklus III meliputi penyusunan rencana pelaksanaan pembelajaran yang dilengkapi dengan strategi PAIKEM Terpadu. Penyusunan rencana pelaksanaan pembelajaran (RPP) dilakukan dengan cara memerbaiki dengan menyesuaikan program pembelajaran yang telah dibuat di awal semester. RPP disusun sesuai dengan model RPP yang dilengkapi dengan strategi PAIKEM Terpadu. Dalam penyusunan rencana pelaksanaan Pembelajaran strategi Paikem pada penelitian tindakan di siklus II dan siklus III tidak ada perbedaan yang signifikan, tetap menerapkan sistem pembelajaran PAIKEM. Prinsip diadakan siklus III karena 
hasil siklus II belum mencapai nilai ketuntasan minimal (KKM) yang digunakan sebagai acuan dalam penelitian tindakan kelas.

Pada siklus ini disebar lembar pengamatan kreativitas peserta didik dirancang untuk melakukan pengamatan dan penilaian pada siklus I, II dan III dengan menggunakan angket penelitian yang disebarkan kepada semua peserta didik di SMP Negeri 2 Legok. Lembar pengamatan guru dirancang untuk melakukan pengamatan pada aspek guru, guru mengucapkan salam, berdoa, mengisi daftar hadir, menyampaikan indikator, tujuan pembelajaran, memberikan apersepsi, mengajar dengan menggunakan media pembelajaran secara kontekstual, ${ }^{20}$ melakukan inovasi baru dengan menggunakan media dalam belajar, dapat menguasai kondisi kelas, memberikan kesempatan anak untuk bertanya, menguasai materi yang diajarkan serta memberikan materi dengan bantuan media yang sesuai, memberikan postes, menyimpulkan pelajaran dan doa penutup.

\section{RPP SMP Negeri 2 Legok}

Pada bagian pendahuluan dilakukan dengan: (i) Guru masuk memberi salam dan doa bersama peserta didik; (ii) Guru melakukan presensi; (iii) Guru melakukan apersepsi? (Bertanya); (iv) Guru menginformasikan topik dan tujuan pembelajaran sesuai meteri yang akan dipelajari; (v) Guru memberikan motivasi kepada peserta didik agar bersemangat belajar; (vi) Guru menyiapkan media pembelajaran yang akan digunakan.

Pada bagian Kegiatan Inti untuk menerapkan strategi PAIKEM Terpadu dengan tiga bagian, yaitu Eksplorasi yang terdiri dari (i) Guru menyiapkan materi yang akan dipelajari yaitu "Allah Maha Pengampun"; (ii) Guru menunjukkan media terkait materi : Balon dan Sulap Tali Temali; (iii) Guru memberikan pertanyaan pada peserta didik terkait dengan media (bertanya); (iv) Guru memberikan umpan balik terhadap jawaban peserta didik. Selanjutnya bagian Elaborasi terdiri dari (i) Guru membagi peserta didik dalam beberapa kelompok (disesuaikan dengan jumlah peserta didik dikelas) dengan breakout room; (ii) Guru membagi media, dan lembar kerja sebagai bahan diskusi pada tiap kelompok; (iii) Setiap kelompok ditugaskan untuk melakukan pengamatan (Inkuiri); (iv) Peserta didik bersama kelompoknya mendiskusi hasil pengamatan kemudian menuliskan dilembar kerja (Masyarakat belajar); (v) Setiap kelompok mempresentasikan hasil diskusi (pemodelan); (v) Kelompok lain memberi

${ }^{20}$ Cocom Komalasari, Pembelajaran Kontektual (Bandung: Rafika Aditama, 2014). 
tanggapan. Tahapan selanjutnya adalah Konfirmasi yang terdiri dari (i) Guru memberikan konfirmasi terhadap hasil kerja peserta didik (refleksi); (ii) Guru memberikan penguatan (reinforcement) kepada peserta didik yang berhasil menjawab pertanyaan dengan benar; (iii) Guru memberikan motivasi kepada peserta didik yang kurang optimal dalam mengikuti kegiatan pembelajaran.

Pada bagian Penutup tindakan yang dilakukan (i) Guru bersama peserta didik menyimpulkan materi yang sudah dibahas (refleksi yang disertai kesaksian); (ii) Peserta didik diberi kesempatan untuk bertanya; (iii) Guru memberikan soal evaluasi; (iv) Hasil pengerjaan diberikan kepada guru; (v) Guru memberikan angket untuk diisi; (vi) Guru menutup pembelajaran (doa dan salam).

\section{Hasil Pengamatan}

Hasil pengamatan belajar PAK diperoleh dengan melakukan tes tertulis pada akhir pelajaran. Dari hasil pengamatan dengan menggunakan strategi PAIKEM Terpadu, pembelajaran berjalan dengan baik. Dalam strategi PAIKEM Terpadu, peserta didik dibagi dalam beberapa kelompok melalui breakout room, peserta didik sangat antusias dan kreatif dalam kelompok. Guru menggunakan metode bervariasi yaitu, ceramah, tanya jawab, diskusi, persentase serta menggunakan media yaitu, tali magic, kartu kejujuran, share screen powerpoin, dan bermain peran. Hasil pengamatan kreativitas belajar melalui angket di SMP Negeri 2 Legok nampak pada tabel berikut:

Tabel 3. Aktivitas Belajar di SMP Negeri 2 Legok Peserta didik pada Siklus III

\begin{tabular}{clc}
\hline No & \multicolumn{1}{c}{ Kualifikasi } & Jumlah Peserta Didik \\
\hline 1 & Kurang & 0 \\
\hline 2 & Cukup & 0 \\
\hline 3 & Baik & 16 \\
\hline 4 & Sangat Baik & 13 \\
\hline
\end{tabular}

Terdapat 29 peserta didik (100\%) mencapai rerata skor kreativitas belajar lebih besar 2,51 (kualifikasi baik) pada siklus III. Rerata skor aktivitas adalah 3,21 . 
Grafik 1. Grafik Kreativitas Belajar di SMP Negeri 2 Legok

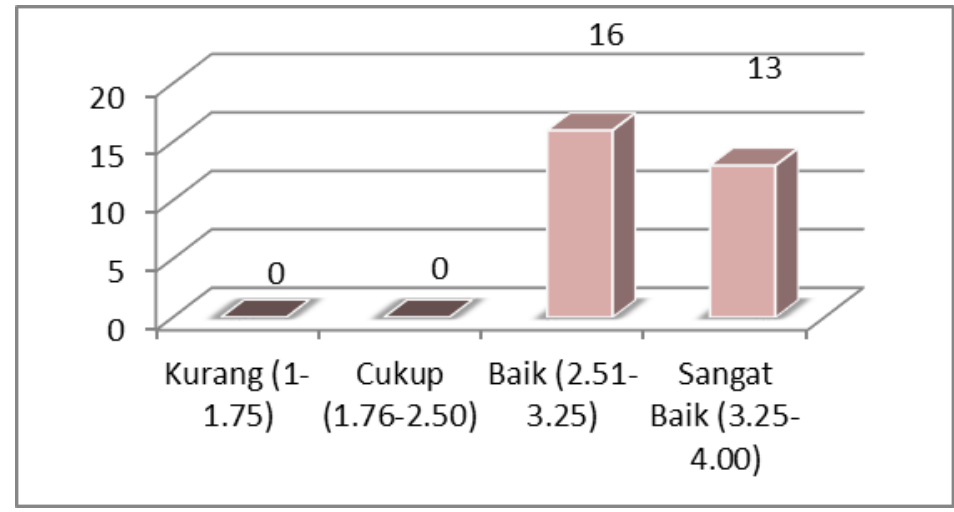

Sedangkan hasil belajar Pendidikan Agama Kristen pada siklus II dapat dilihat pada tabel berikut:

Tabel 4. Hasil Belajar di SMP Negeri 2 Legok pada Siklus III

\begin{tabular}{ccc}
\hline No & Aspek & Nilai \\
\hline 1 & Nilai Terendah & 95 \\
\hline 2 & Nilai Tertinggi & 100 \\
\hline 3 & Rata-rata Nilai & 97,3 \\
\hline
\end{tabular}

Terdapat 29 peserta didik (100\%) memeroleh hasil belajar Pendidikan Agama Kristen berupa nilai tes tertulis lebih besar atau sama dengan 78 (memenuhi KKM) pada siklus III. Data tersebut dapat divisualisasi dengan grafik berikut:

Grafik 2. Grafik Hasil Belajar di SMP Negeri 2 Legok Siklus III

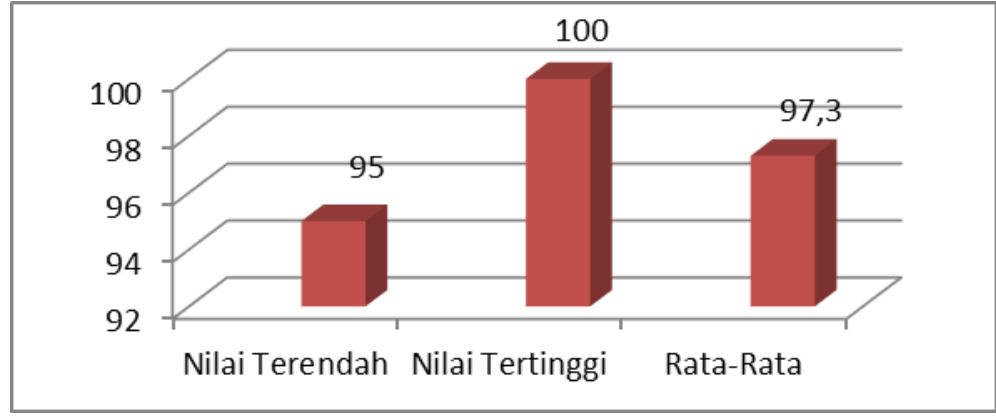

Ketuntasan prestasi belajar PAK berdasarkan hasil tes tertulis sebesar $100 \%$ atau 29 orang dari 29 peserta didik dan terdapat $0 \%$ atau 0 orang dari 29 peserta didik yang belum tuntas. Hal ini menunjukan bahwa hasil belajar PAK berupa nilai tes tertulis SMP Negeri 2 Legok mengalami peningkatan. 
Hasil pengamatan peran guru dalam menerapkan pembelajaran simulasi pada pembelajaran PAK diamati dengan menggunakan lembar observasi. Ada sebelas yang diamati yaitu Sedangkan lembar pengamatan guru dirancang untuk melakukan pengamatan pada aspek guru, guru mengucapkan salam, berdoa, mengisi daftar hadir, menyampaikan indikator, tujuan pembelajaran, memberikan apersepsi, mengajar dengan menggunakan media pembelajaran secara kontekstual, melakukan inovasi baru dengan menggunakan media dalam belajar, ${ }^{21}$ dapat menguasai kondisi kelas, memberikan kesempatan anak untuk bertanya, menguasai materi yang diajarkan serta memberikan materi dengan bantuan media yang sesuai, memberikan postes, menyimpulkan pelajaran dan doa penutup.

\section{Hasil Penerapan Strategi PAIKEM Terpadu}

Penelitian tindakan kelas ini terdiri dari 3 siklus di SMP N 2 Legok Banten. Penerapan strategi PAIKEM Terpadu dilakukan pada siklus I dan II. Penggunaan strategi PAIKEM Terpadu ternyata berdampak pada kreativitas belajar peserta didik dan hasil belajar peserta didik seperti yang dilakukan oleh Nila dkk ketika menerapkannya dalam mata pelajaran IPS di SMP Negeri 45 Palembang. ${ }^{22}$ Di akhir siklus III, peneliti menyebarkan angket untuk mengetahui pengaruhnya strategi PAIKEM Terpadu khusus kreativitas bagi peserta didik. Dan hasil dari angket tersebut di hitung dalam bentuk skor. Hasil belajar PAK di SMP Negeri 2 Legok diperoleh dari nilai tes tertulis menunjukan peningkatan dari siklus I ke siklus II dan Siklus III. Hasil kenaikan dapat dilihat pada tabel berikut:

Tabel 5. Peningkatan Hasil Belajar di SMP Negeri 2 Legok

\begin{tabular}{|l|c|c|c|l|}
\hline \multicolumn{1}{|c|}{ Nilai } & $\begin{array}{c}\text { Siklus } \\
\text { I }\end{array}$ & $\begin{array}{c}\text { Siklus } \\
\text { II }\end{array}$ & $\begin{array}{c}\text { Siklus } \\
\text { III }\end{array}$ & $\begin{array}{l}\text { Refleksi dari kondisi awal } \\
\text { ke kondisi akhir }\end{array}$ \\
\hline Nilai minimum & 70 & 70 & 95 & Nilai minimum naik 25 \\
\hline $\begin{array}{l}\text { Nilai } \\
\text { maksimum }\end{array}$ & 80 & 85 & 100 & Nilai maksimum naik 20 \\
\hline Rata-rata nilai & 75 & 77,5 & 97,3 & Rata-rata nilai naik 22,5 \\
\hline
\end{tabular}

${ }^{21}$ H. Tukiran Taniredja, Model-Model Pembelajaran Inovatif (Bandung: Alfabeta, 2012).

${ }^{22}$ Nila Utami and Djahir Basir, "Pengaruh Penerapan Model Pembelajaran Paikem Pada Mata Pelajaran IPS," URNAL PROFIT 2, no. 1 (2015): 68-76. 
Dengan melihat ketuntasan hasil belajar maka dari siklus III telah mencapai indikator tersebut. Sedangkan siklus I dan II tidak mencapai indikator kinerja, dikarenakan pada siklus I tidak diterapkannya strategi PAIKEM Terpadu. Melalui penerapan strategi PAIKEM Terpadu dapat meningkatkan prestasi belajar PAK di SMP Negeri 2 Legok dari siklus I ketuntasan terdapat $13 \%$, dan di siklus II ketuntasan hanya $51,7 \%$ menjadi $100 \%$ pada siklus III. Hasil pengamatan ditemukan bahwa terdapat 29 peserta didik yang aktif mengikuti pelajaran PAK. Untuk mengetahui karakteristik startegi PAIKEM Terpadu apa yang paling dominan pada pembelajaran Pendidikan Agama Kristen di SMP Negeri 2 Legok peneliti menyebarkan angket 15 karakteristik guru kepada siswa. ${ }^{23}$

Terdapat 15 karakteristik yang terdapat pada strategi PAIKEM Terpadu yang di terapkan pada pembelajaran PAK yaitu: pribadi $(3,16)$, luwes $(3,21)$, bermakna $(3,17)$, holistik $(3,15)$, otentik $(3,51)$, aktif $(3,19)$, kreatif $(3,11)$, efektif $(3,25)$, komulatif 3,16$)$, keterlibatan peserta didik $(3,27)$, inovatif $(3,09)$, reflektif $(3,1)$, hasil karya peserta didik $(3,2)$, hasil belajar $(3,31)$, menyenangkan $(3,4)$. Data tersebut dapat divisualisasi dengan grafik berikut ini:

Grafik 3. Grafik Hasil Strategi PAIKEM Terpadudi di SMP Negeri 2 Legok

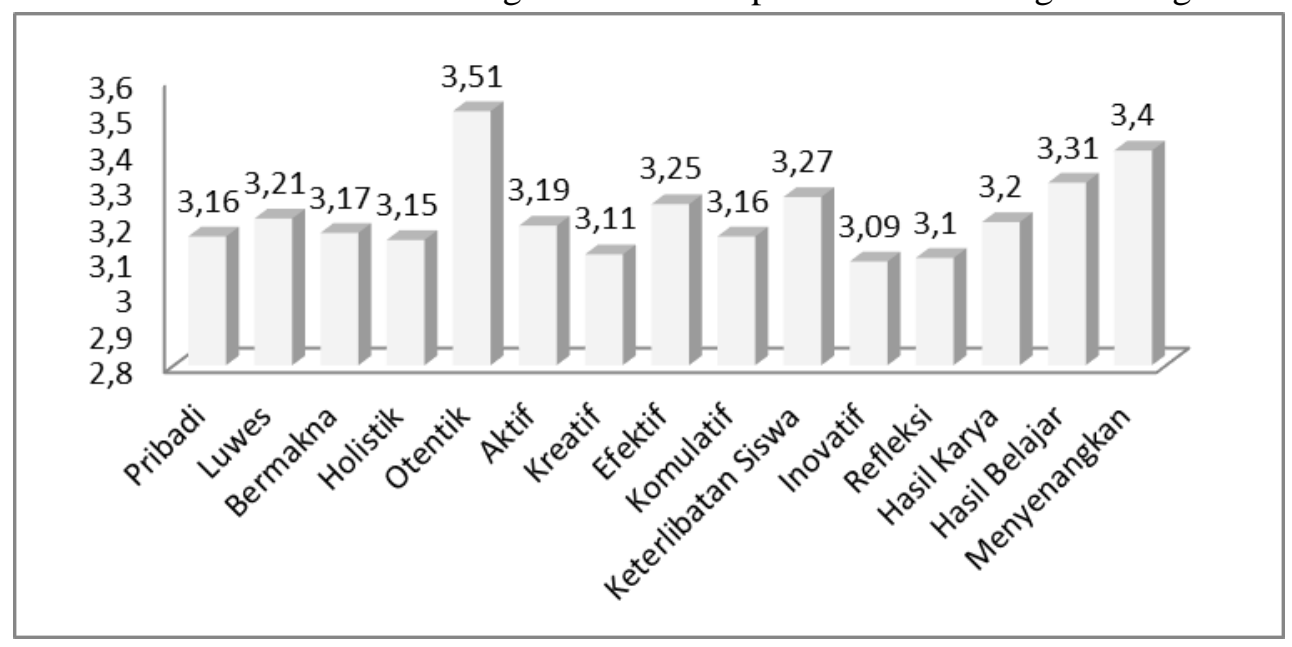

Dari data tersebut, karakteristik strategi PAIKEM Terpadu yang diterapkan di SMP Negeri 2 Legok yang paling dominan adalah karakteristik otentik dengan nilai rata-rata $3,51 \%$.

Dari pemaparan di atas, maka kesimpulan penelitian penerapan strategi PAIKEM Terpadu telah mencapai tataran tinggi yang dilakukan melalui 2011).

${ }^{23}$ Daniel Muijs and David Reynold, Efective Teaching (Yogyakarta: Pustaka Pelajar, 
pelajaran daring. Lebih lanjut dipertimbangkan untuk menggunakan model pembelajaran kombinasi (daring-luring) dan juga dapat menggunakan model ansinkronus dan sinkronus jika pandemi masih berlanjut. Serta guru mengupgrade skill dan pengetahuan terkait literasi digital. ${ }^{24}$ Guru PAK di masa pandemi perlu melek teknologi digital. Supaya guru PAK menjadi lebih kreatif dalam proses pembelajaran daring PAK. ${ }^{25}$

\section{Simpulan}

PAIKEM Terpadu yang telah diterapkan secara berkala di SMP Negeri 2 Legok Banten memberikan wawasan serta strategi bagi para pendidik PAK agar melaksanakan pembelajaran yang lebih aktif, inovatif, kreatif, efektif dan menyenangkan bagi peserta didik. Keharusan ini ditujukan agar kualitas dari peserta didik dapat meningkat. Selain itu strategi pembelajaran PAIKEM Terpadu, dapat menjadi strategi pembelajaran alternatif di masa dan post pandemi sekalipun menggunakan platform digital. Melihat dampaknya yang signifikan, maka pada tataran kebijakan penting untuk mewujudkan program merdeka belajar memlalui penerapan strategi PAIKEM Terpadu. Sehingga tercipta kemandirian belajar siswa pada mata pelajaran Pendidikan Agama Kristen. Strategi yang dapat dilakukan adalah dengan meningkatkan mutu guru khususnya guru PAK, Penguatan organisasi sekolah di bidang pembelajaran, Peningkatan alat bantu pembelajaran, penyadaran terhadap gereja (antar denominasi) pentingnya PAK di sekolah-sekolah di mana ada anak dari anggota jemaatnya bersekolah tetapi sekolah tersebut guru Agama Kristen belum ada.

\section{Daftar Pustaka}

Basar, Afip Miftahul. "Problematika Pembelajaran Jarak Jauh Pada Masa

Pandemi Covid-19." Edunesia : Jurnal Ilmiah Pendidikan 2, no. 1 (2021): 208-218.

Benyamin, Priskila Issak, Ibnu Salman, and Frans Pantan. "Evaluasi

Pembelajaran Daring Pendidikan Agama Kristen Di Masa Pandemi."

Jurnal Teologi Berita Hidup 4, no. 1 (2021): 52-59.

Benyamin, Priskila Issak, Ucok P Sinaga, and Febie Yolla Gracia. "Penggunaan 'Platform' Digital Pada Pembelajaran Pendidikan Agama Kristen Di Era

${ }^{24}$ Priskila Issak Benyamin, Ucok P Sinaga, and Febie Yolla Gracia, "Penggunaan 'Platform' Digital Pada Pembelajaran Pendidikan Agama Kristen Di Era Disrupsi," REGULA FIDEI: Jurnal Pendidikan Agama Kristen 6, no. 1 (2021): 60-68.

${ }^{25}$ Dewi Salma Prawiradilaga, Wawasan Teknologi Pendidikan (Jakarta: Kencana Prenada Media Group, 2018). 
Disrupsi." REGULA FIDEI: Jurnal Pendidikan Agama Kristen 6, no. 1 (2021): 60-68.

Busyra, Sarah, and Lutfiah Sani. "Kinerja Mengajar Dengan Sistem Work From Home (WFH) Pada Guru Di SMK Purnawarman Purwakarta." IQ (Ilmu Alqur'an): Jurnal Pendidikan Islam 3, no. 01 (2020): 1-16.

Djwandono, Sri Esti Wuryani. Psikologi Pendidikan. Jakarta: Gramedia Widiasarana Indonesia, 2006.

Gitleman, Lisa. "Penerapan Metode PAIKEM Untuk Hasil Belajar Siswa Dalam Mata Pelajaran Pendidikan Agama Kristen Di Kelas VB SD Inpres Oebufu Kupang." Paper Knowledge . Toward a Media History of Documents 1, no. 2 (2014): 15-20.

Haerullah, Ade, and Said Hassan. PTK \& Inovasi Guru. Edited by Eko Purnomo and Hernita Pasongli. Cetakan 1. Ponorogo: Uwais Inspirasi Indonesia, 2021.

Handayani, Lina. "Keuntungan, Kendala Dan Solusi Pembelajaran Online Selama Pandemi Covid-19 : Studi Ekploratif Di SMPN 3 Bae Kudus." Journal Industrial Engineering \& Management Research 1, no. 2 (2020): 16.

Hutauruk, Agusmanto, and Ropinus Sidabutar. "Kendala Pembelajaran Daring Selama Masa Pandemi Di Kalangan Mahasiswa Pendidikan Matematika: Kajian Kualiatatif Deskriptif." SEPREN: Journal of Mathematics Education and Applied 02, no. 01 (2020): 45-51.

Impriyan, Anindia. "Penggunaan Media Power Point Dalam Pelaksanaan Sistem PAIKEM Pada Mata Pelajaran Fikih Kelas IX Pada Masa Pandemi Covid19 Di MTs Nahdlotussibyan Wonoketingal Karangayar Demak." IAIN Kudus, 2020.

Indrapangastuti, Dewi. "Praktek Dan Problematik Pendidikan Multikultural Di

SMK." Jurnal Pembangunan Pendidikan: Fondasi dan Aplikasi 2, no. 1 (2014): 13-25.

Komalasari, Cocom. Pembelajaran Kontektual. Bandung: Rafika Aditama, 2014.

Magdalena, Ina, Nevi Septianti, Lisa Barlianty, and Sitti Aisyah Farawansya. "PENERAPAN MODEL PEMBELAJAN PAIKEM GEMBROT DIMASA PANDEMI COVID-19 TERHADAP PENINGKATAN." EDISI: Jurnal Edukasi dan Sains 2 (n.d.): 348-365.

Malik, Abdul. "Penerapan Model PAIKEM Dalam Meningkatkan Hasil Belajar." Education and Learning Journal 1, no. 1 (2020): 50.

Matulessy, Yulita, Vivi Guslauw, and Shintya Lumasina. "METODE PEMBELAJARAN PAIKEM DALAM MEWUJUDKAN MERDEKA BELAJAR SISWA DI MASA PANDEMI COVID-19 PAIKEM' S LEARNING METHODS IN REALIZING STUDENTS ' LEARNING INDEPENDENCE DURING THE COVID-19 PANDEMIC" (2021). 
244 Fidei: Jurnal Teologi Sistematika dan Praktika, Vol. 4, No. 2, Des. 2021

Muijs, Daniel, and David Reynold. Efective Teaching. Yogyakarta: Pustaka Pelajar, 2011.

Oci, Markus. "Pengaruh Pengelolaan Kelas Dalam Pelajaran Agama Kristen Terhadap Prestasi Belajar Siswa Di SMP Kanaan Ungaran Tahun Ajaran 2017-2018." FIDEI: Jurnal Teologi Sistematika dan Praktika 1, no. 2 (2018): 199-218.

Prawiradilaga, Dewi Salma. Wawasan Teknologi Pendidikan. Jakarta: Kencana Prenada Media Group, 2018.

Siahaan, Matdio. "Dampak Pandemi Covid-19 Terhadap Dunia Pendidikan." Jurnal Kajian Ilmiah (JKI) 1, no. 1 (2020): 1-6.

Suprijono, Agus. Cooperatif Learning, Teori Dan Aplikasi PAIKEM. 5th ed. Yogyakarta: Pustaka Pelajar, 2011.

Toisuta, Jakson Sespa. "Peran Dosen Mengatasi Permasalahan Pembelajaran Online Pada Masa Pandemi Covid-19." Fidei: Jurnal Teologi Sistematika dan Praktika 4, no. 1 (2021): 23-42.

Trianto. Model Pembelajaran Terpadu: Konsep, Strategi, Dan Implementasinya Dalam Kurikulum Tingkat Satuan Pendidikan. Jakarta: Bumi Aksara, 2011. Tukiran Taniredja, H. Model-Model Pembelajaran Inovatif. Bandung: Alfabeta, 2012.

Utami, Nila, and Djahir Basir. "Pengaruh Penerapan Model Pembelajaran Paikem Pada Mata Pelajaran IPS.” URNAL PROFIT 2, no. 1 (2015): 6876. 